\title{
FUEL EXTRACTION FROM THERMOCOL WASTE
}

\author{
Hafis Muhammed ${ }^{1}$, Sreenivas $\mathbf{P}^{2}$ \\ ${ }^{I}$ MTech student, Energy Management, Govt. Model Engineering College, Kerala, India \\ ${ }^{2}$ Assistant Professor, Mechanical Engineering, Govt. Model Engineering College, Kerala, India
}

\begin{abstract}
Thermocol is the expanded form of Polystyrene which is a plastic very commonly used in its hard form as well as expanded foam. Thermocol is a brand name given by the company BASF. This material finds wide usage in the packaging industry, model and craft industry as well as in the construction and insulation industry. Thermocol is slow to biodegrade and is therefore a focus of controversy among environmentalists. Thermocol does not biodegrade for hundreds of years and is resistant to photolysis. Animals do not recognize polystyrene foam as an artificial material and may even mistake it for food. It blows in the wind and floats on water, due to its low specific gravity. It can have serious effects on the health of birds or marine animals that swallow significant quantities. It is increasingly abundant as a form of litter in the outdoor environment, particularly along shores and waterways, especially in its foam form, and also in increasing quantities in the Pacific Ocean. The primary objective of this paper is to provide a solution for the disposal of increasing amount of thermocol wastes in our society. A pyrolysis plant has been setup for extracting fuel from this thermocol waste and to find a way to decrease the use of fossil fuels.
\end{abstract}

\section{INTRODUCTION}

For more than 50 years, global production of plastic has continued to rise. Some 299 million tons of plastics were produced in 2013, representing a 4 percent increase over 2012. Recovery and recycling, however, remain insufficient, and millions of tons of plastics end up in landfills and oceans each year [1].According to the United Nations Environmental Program, between 22 percent and 43 percent of the plastic used worldwide is disposed of in landfills, where its resources are wasted, the material takes up valuable space, and it blights communities. Recovering plastic from the waste stream for recycling or for combustion for energy generation has the potential to minimize these problems. However, much of the plastic collected for recycling is shipped to countries with lower environmental regulation. And burning plastic for energy requires air emissions controls and produces hazardous ash, all while being relatively inefficient.

Polystyrene or commonly known as thermocol is also a type of plastic made from the monomer styrene through suspension polymerization. After polymerization is complete, the mixture consisting of beads made up of polystyrene chains is cooled. These beads are then washed out and dried. Then they are sorted to achieve uniform bead size. These beads are heated with steam to lower the density of them. Then they are aged for about a day which allows the air to diffuse into them and make them harder. After aging, these beads can be molded in to desired shape.

Today, there is no special treatment for the thermocol waste and most of the them after use find space in the landfills. Its volume is high and hence take up a lot of space. It is extremely light and floats on water and becomes a choking hazard for river and sea creatures. It is highly flammable and on burning releases carcinogenic fumes. In the case of Thermocol, the recycling process is fairly simple and can be recycled without much material loss up to 20 times, but the cost of the recycling machinery is too high for anonmanufacturer to invest in. There isn't much difference in the cost of new thermocol sheets compared to the recycled thermocol sheets.

Burning of these thermocol waste does not give a solution as it can cause serious environmental problems. Another method of thermocol waste management is to dissolve them in acetone or orange oil thereby reducing its size to about 20 times. Dissolving in acetone makes a clay like substance and dissolving in orange oil makes it a great adhesive.

Scientists are now researching in the field of converting waste plastics into fuel [2]. The pyrolysis process is one of the most promising technologies in the conversion of waste plastics into high quality oil. During pyrolysis, plasticpolymers are thermally degraded by heating them in the absence of oxygen. The main products of thepyrolys is process are liquid and gaseous, producing only a small amount of solid.

This paper elaborates the experimental setup for the conversion of thermocol waste into liquid fuel.

\section{CONVERSION PROCESS}

The process involves two steps: size reduction and pyrolysis. The major difficulty raised during the pyrolysis process is the density of thermocol. It occupies huge space compared to its weight. Hence the size of the pyrolysis chamber has to be made significantly larger to occupy more solid waste. One another idea is to reduce the size of thermocol thereby increasing its density before taking it to 
the pyrolysis chamber. Different methods can be adopted to reduce the thermocol size like heating, dissolving in polystyrene solution etc. Heat treatment offers a better method of size reduction as it effectively reduces the size by a larger margin.

\subsection{Size Reduction}

The size of thermocol wastes has to be limited in order to reduce the size of the pyrolysis chamber. A machine has been fabricated to reduce the size of thermocol as shown in figure below. The major parts of this machine include a conical container, a resistance heater, a stand and an electrical supply.

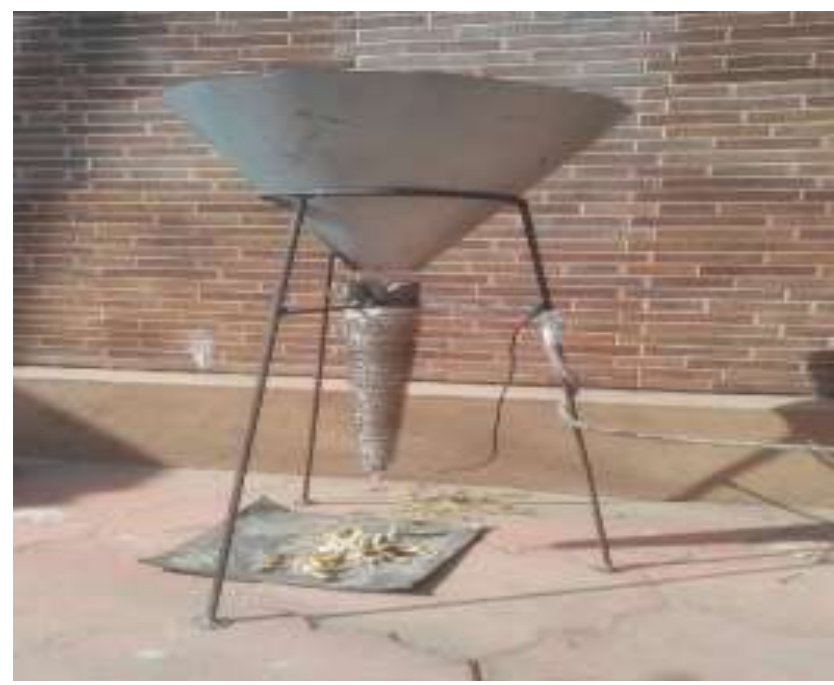

Fig -1: Equipment to reduce thermocol size

Thermocol is shredded into various small pieces and is fed to the conical container. The bottom of the conical container directs the waste pieces to another metallic plate wounded with electric heater. The metallic plate and the electric heater are separated by fiber glass tape to avoid short circuit. When the supply is put on the heater becomes hot and the heat is transferred to the thermocol waste falling through the metallic plate by radiation. Thus, we get thermocol with higher density at the outlet as shown in figure below.

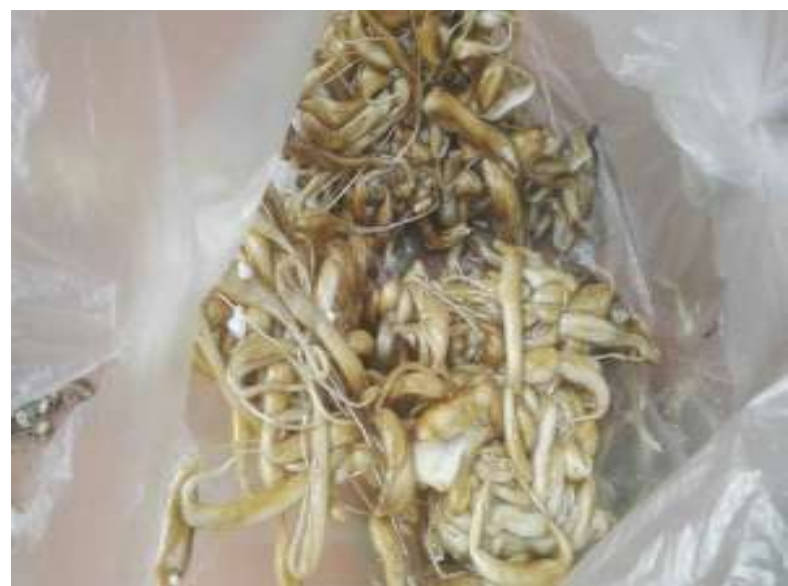

Fig -2: Reduced thermocol

\subsection{Pyrolysis Process}

The reduced thermocol can now undergo pyrolysis. A schematic diagram of the pyrolysis plant is shown below. Here the solid wastes are placed inside a container called pyrolysis chamber which is well sealed. The chamber is now heated to a higher temperature in the range of about 600 degrees Celsius. At the top of the chamber the gases can escape through a copper tube which acts as condenser. Water cooling is provided to the copper tube and the gases gets condensed in the tube. To ensure complete condensation the end of copper tube is attached to a glass condenser. At the exit of the gas condenser we get the pyrolysis oil.

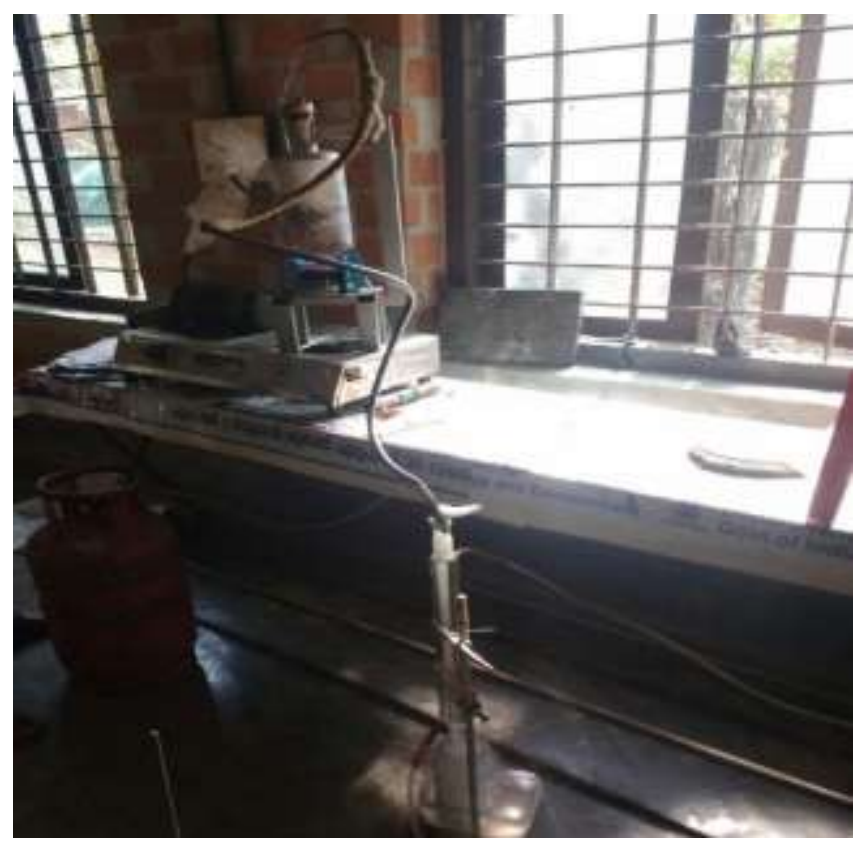

Fig -3: Pyrolysis plant

\section{RESULTS AND DISCUSSIONS}

\subsection{Yield of Pyrolysis Process}

The thermocol does not loss its weight considerably during heat treatment and one kilogram of thermocol produces just above one liter of pyrolysis oil. Initially 520 grams of waste thermocol was taken. After heat treatment the size of this thermocol waste has fallen to 480 grams. This shows that there isn't any significant loss during this process.

Again 2 kilograms of heat treated thermocol when undergone pyrolysis, produced about 2.2 liters of pyrolysis oil. This indicates that from one kilogram of thermocol waste we can produce just above one liter of pyrolysis oil showing an oil recovery factor of $1 \mathrm{~L} / 1 \mathrm{~kg}$ of thermocol waste. 


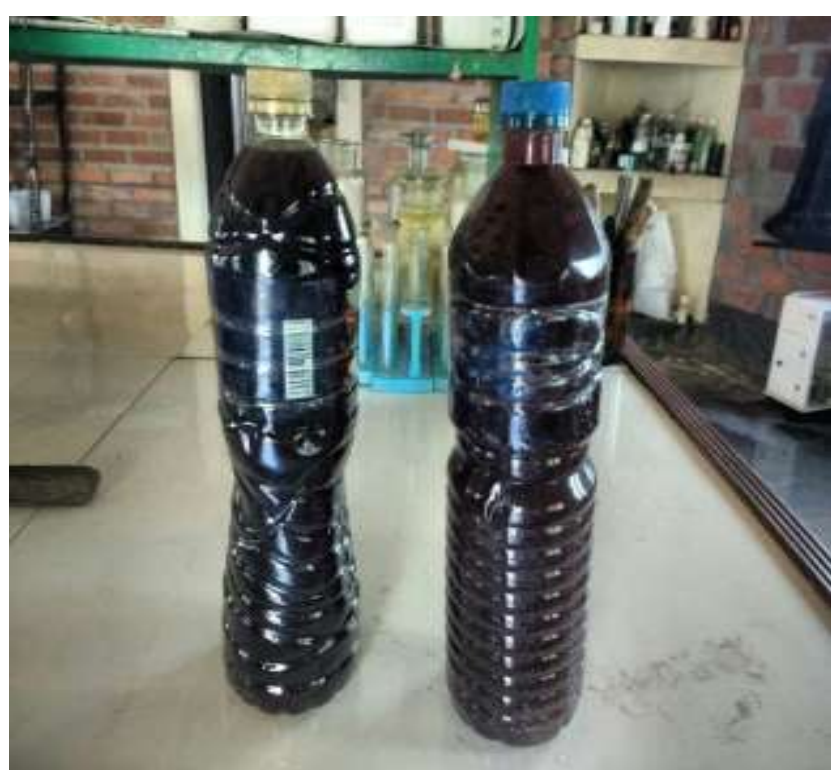

Fig -4: Pyrolysis oil

\subsection{Flash Point and Fire Point}

Flash point of a volatile material is the lowest temperature at which vapors of the material will ignite, when given an ignition source. Fire point is the lowest temperature at which the vapors of the material will keep burning after being ignited and the ignition source removed. The fire point is higher than the flash point, because at the flash point more vapor may not be produced rapidly enough to sustain combustion.

The flash point of the pyrolysis oil from thermocol waste was found out to be 38 degrees Celsius and fire point was found to be 40 degrees Celsius.

\section{CONCLUSION}

Pyrolysis of thermocol waste into oil not only produces a solution to the never-ending problems of solid waste treatment but also provides an alternative for the exhausting fossil fuels. The flash point and fire point values of the oil produced resembles the values of diesel and can be used to blend with diesel fuel for running various machineries. It can also be used as a cooking gas substituting the use of kerosene gas in household applications. Filling the landfills with solid thermocol does not do any good to the society and incineration of this waste causes serious environmental problems. Hence converting it to an oil shows an effective way for treatment of these solid wastes.

\section{FUTURE SCOPE}

The feasibility of the liquid fuel produced can be assessed through load test in engines and the compatibility of the fuel with other fossil fuels can be tested. However, emission properties are a matter of concern. The properties of combustion are to be analyzed and better emission control mechanisms are to be suggested.

\section{REFERENCES}

[1]. Gaelle Gourmelon, 'Global production rises, recycling lags', An online article by Worldwatch Institute, 2009.

[2]. American Chemistry Council, 'How Plastics are made?', 2005

[3]. Ioannis Kalargaris, Guohong Tian, Sai Gu, 'The utilization of oils produced from plastic waste at different pyrolysis temperatures in a DI diesel engine', Elsevier, 2017.

[4]. Ioannis Kalargaris, Guohong Tian, Sai Gu, 'Combustion, performance and emission analysis of a DI diesel engine using plastic pyrolysis oil, Elsevier, 2017.

[5]. Harsha Vardhan Reddy T, Aman Srivastava, Vaibhav Anand and Saurabh Kumar, "Fabrication and Analysis of a Mechanical System to Convert Waste Plastic into Crude Oil", International Journal of Emerging Technology and Advanced Engineering, 2016. 